\title{
Primary malignant mesothelioma of the spermatic cord
}

\author{
Zeeshan Ahmed, ${ }^{1}$ Suresh Singh, ${ }^{1}$ Akshay Mangal, ${ }^{1}$ Alka Mittal ${ }^{2}$
}

'Division of Surgical Oncology, SMS Medical College and Hospital, Jaipur, Rajasthan, India

${ }^{2}$ Department of Pathology, SMS Medical College and Hospital, Jaipur, Rajasthan, India

\section{Correspondence to}

Dr Zeeshan Ahmed, drzeeshan180@gmail.com

Accepted 11 March 2016

\section{SUMMARY}

Primary spermatic cord malignant mesothelioma is an extremely rare tumour with only 12 cases reported so far. It is an aggressive tumour with a high recurrence rate. A 45-year-old man presented with a slow growing right inguinal swelling for the past 1 year. Physical examination revealed a well-circumscribed, hard, non-reducible swelling palpable along the medial extent of the inguinal canal with no cough impulse. Fineneedle aspiration cytology suggested metastatic carcinoma. Contrast-enhanced CT of the thorax and abdomen did not reveal any primary. Right high inguinal orchidectomy was performed at another institution. Postoperative histopathological examination (HPE) and immunohistochemistry suggested biphasic malignant mesothelioma with resected margin positive. The patient was referred to us for revision surgery and adjuvant therapy. Postoperative course was uneventful. Currently, he is undergoing radiotherapy.

Surgery is the first-line treatment. Patients should receive adjuvant radiotherapy and/or chemotherapy and long-term follow-up surveillance.

\section{BACKGROUND}

Primary malignant mesothelioma (MM) of the spermatic cord is an extremely rare tumour with only 12 cases reported so far in the English medical literature. It is part of a broader group of paratesticular malignant mesotheliomas that constitute $0.3-1.4 \%$ of all malignant mesotheliomas. They are aggressive tumours with high recurrence rate. Treatment options are radical surgery \pm adjuvant therapy. Long-term follow-up surveillance is advisable.

\section{CASE PRESENTATION}

A 45-year-old man, a truck driver by profession, presented with a right inguinoscrotal swelling for the past 1 year. The swelling was insidious in onset, progressively increasing in size and associated with dull pain. He had no other significant symptoms. He had no history of asbestos exposure.

Medical, social and family history was not significant.

Physical examination revealed a well circumscribed, hard, non-reducible swelling palpable along the medial extent of the inguinal canal with no cough impulse. Bilateral testes were normal on palpation. The rest of the physical examination was normal.

The primary clinical suspicion was a soft tissue sarcoma of the spermatic cord.

\section{INVESTIGATIONS}

A Fine-needle aspiration cytology (FNAC) was performed, which reported cytological features suggestive of metastatic carcinoma. Ultrasound carried out 1 month later reported a $8.2 \times 5.0 \mathrm{~cm}$ solid, heterogeneous right inguinal mass highly suspicious of malignancy.

A contrast-enhanced CT (CECT) of the abdomen and pelvis (figure 1) depicted a well-defined mildly heterogeneously enhancing soft tissue density mass lesion (size $49.6 \times 50.7 \times 68.6 \mathrm{~mm}$ ) in the inguinoscrotal region medially abutting the dorsum of the penis, with a few enlarged mesenteric lymph nodes suggestive of neoplastic pathology.

The testicular tumour markers were $\beta$-human chorionic gonadotropin $(0.4 \mathrm{ng} / \mathrm{mL}), \alpha$-fetoprotein (AFP, $3.1 \mathrm{ng} / \mathrm{mL}$ ), lactate dehydrogenase (LDH) (537 IU/L).

The rest of the routine haematological and biochemical lab investigations were within normal range. CECT of the thorax and abdomen did not reveal any primary.

\section{DIFFERENTIAL DIAGNOSIS}

Considering the location of the tumour in the inguinal canal and a normal scrotal examination, the primary differential considered was a soft tissue sarcoma of the spermatic cord. So a FNAC was carried out. The second differential was a metastatic carcinoma in view of the FNAC report, though the grossly normal CECT of the thorax and abdomen were against it. The raised LDH levels also raised the possibility of a seminomatous germ cell tumour, although the physical examination findings were against it.

\section{TREATMENT}

A right high inguinal orchidectomy was performed at another institution.

\section{OUTCOME AND FOLLOW-UP}

On gross pathological examination, the resected specimen consisted of testes with attached spermatic cord. The testes measured $4 \times 3 \times 3 \mathrm{~cm}$ and were unremarkable on sectioning. The outer surface of the spermatic cord was congested and capsulated. On sectioning, the cut surface showed a solid greyish-white mass measuring $8 \times 4 \times 3.5 \mathrm{~cm}$.

On microscopic examination, it showed a malignant neoplasm with biphasic differentiation. In some areas, epithelial differentiation with polygonal cells and gland formation was seen. In other 


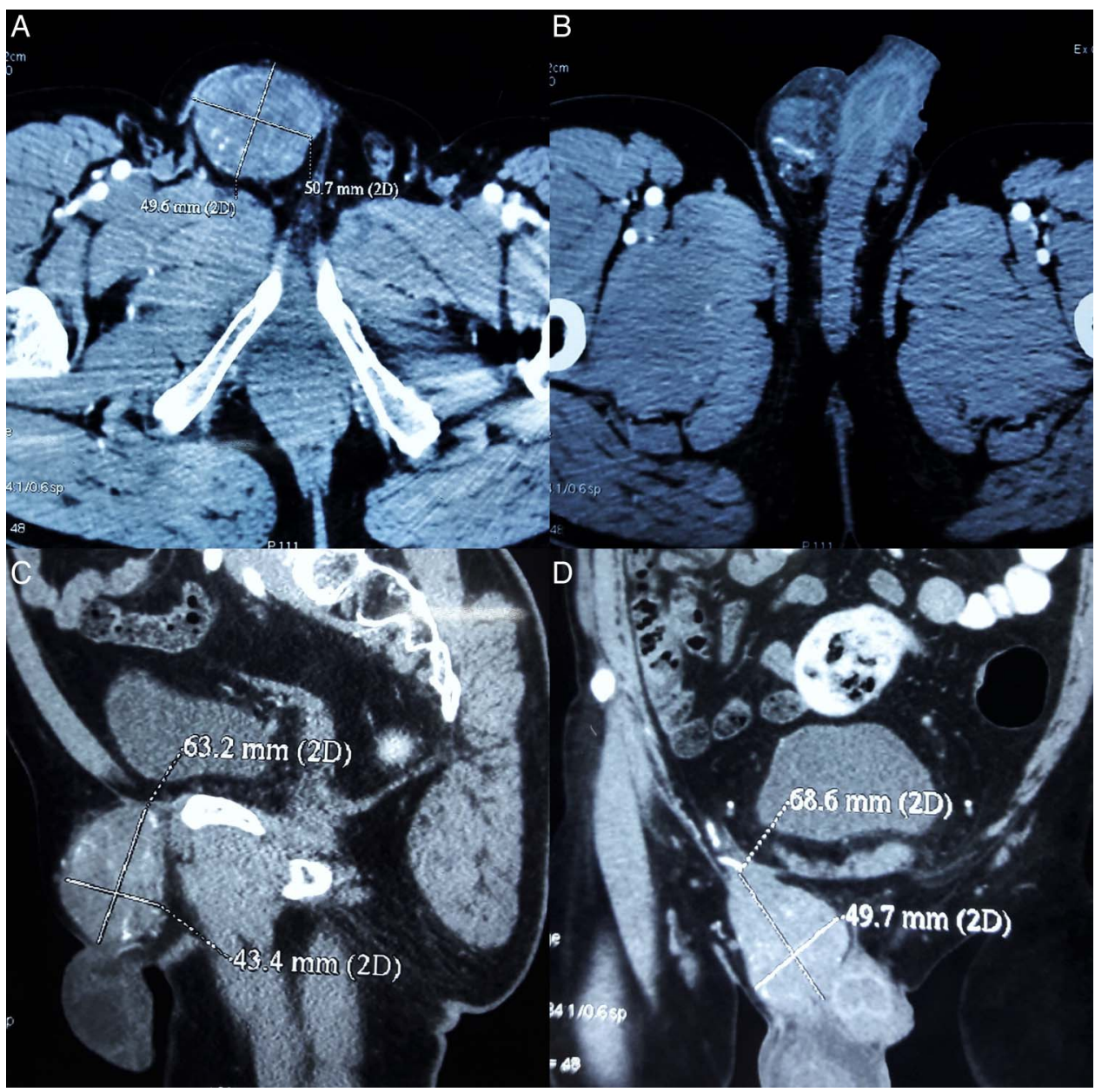

Figure 1 (A and B) CECT of the abdomen and pelvis-transverse section (C). Sagittal section and (D) coronal section depicting well defined lobulated heterogeneously enhancing soft tissue density mass $(49.6 \times 50.7 \times 68.6 \mathrm{~mm})$ in the inguinoscrotal region medially abutting the dorsum of the penis. CECT, contrast-enhanced CT.

areas, the cells were spindle shaped and arranged in bundles resembling sarcomatoid differentiation. Extensive areas of necrosis were seen. Mitotic activity was brisk. The resected end of spermatic cord showed presence of a tumour (figure 2).
Immunohistochemistry examination was positive for mesothelial markers Calretinin, CK 5/6, Vimentin, Pan CK, EMA and CK 7. Negative markers were CEA, MOC31, BerEP4, Bcl2, PLAP, CD30, AFP and WT1 (figure 3).

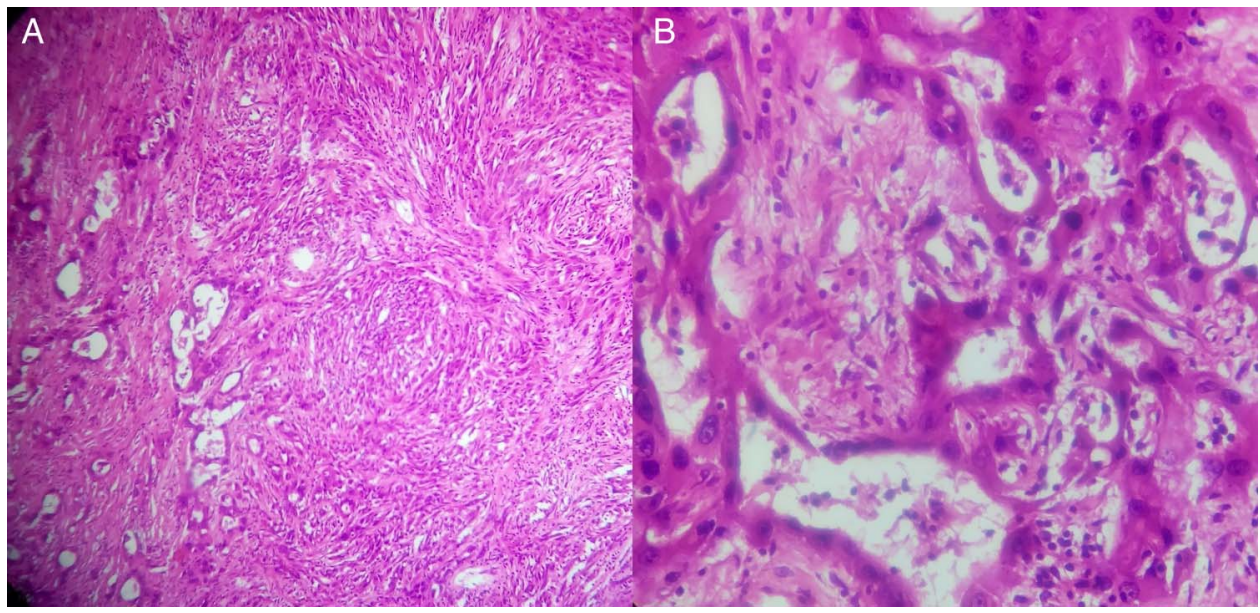

Figure 2 (A) HPE depicting biphasic morphology with epithelial cells forming tubules and sheets, and a sarcomatoid component having numerous spindle cells with stromal invasion and areas of necrosis (H\&E $\times 100)$. (B) Note the cuboidal cells lining the tubules, with high nucleocytoplasmic ratio, mitotic figures (3/50 high-power field) and atypical mitotic figures ( $\& E \times 400)$. 


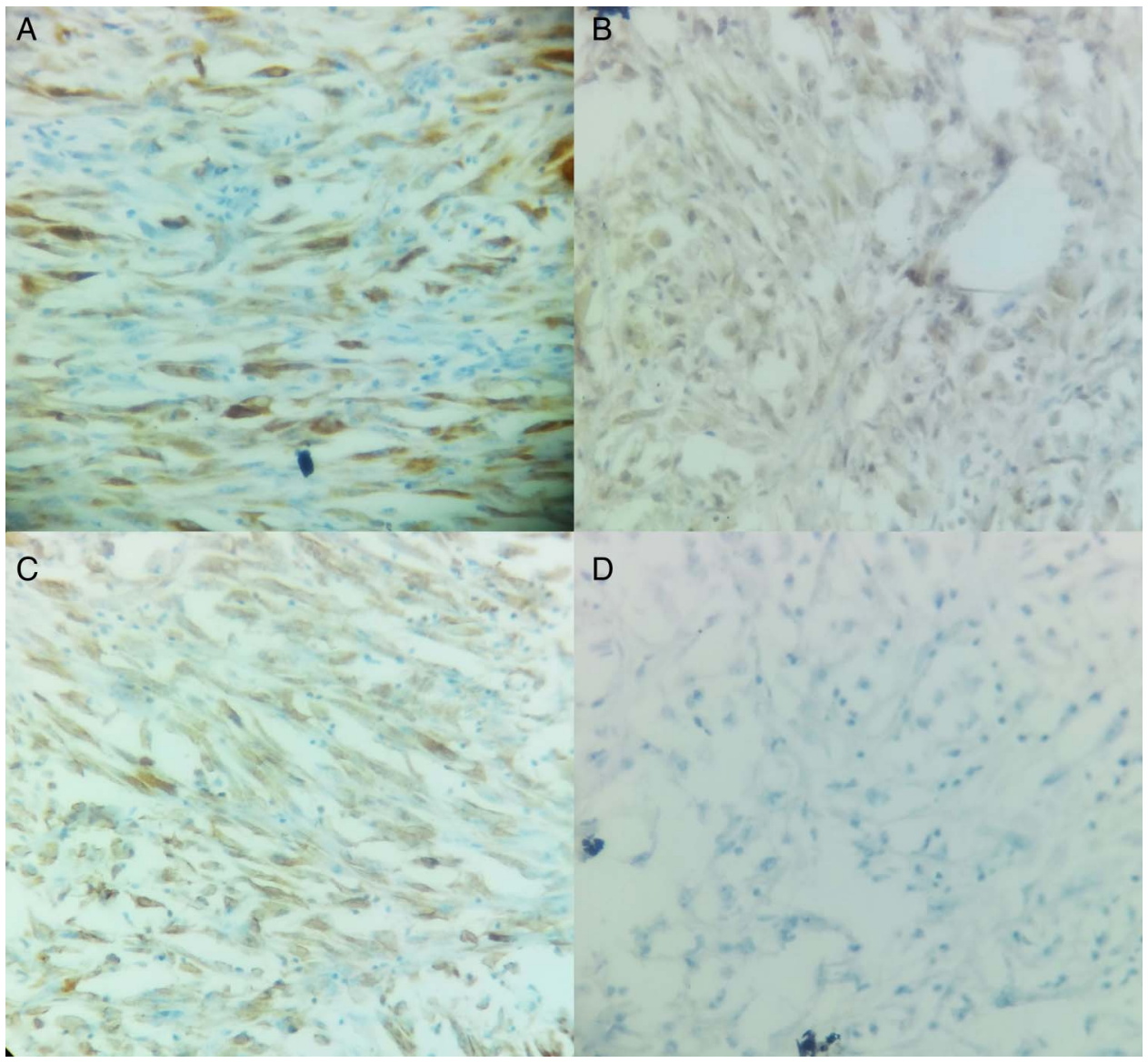

Figure 3 (A) CK 5/6 stained sarcomatoid cells $\times 400$. (B) Calretinin stained sarcomatoid cells $\times 400$. (C) Vimentin stained sarcomatoid cells $\times 400$. (D) CEA negative $\times 400$.

In view of necrosis and infiltration in surrounding soft tissue and positive mesothelial immunomarkers, a definitive postoperative diagnosis of biphasic MM was made.

Subsequently, the patient presented to our institution for revision surgery and adjuvant therapy. The positive spermatic cord margin necessitated a second surgery to resect the cut end of the distal spermatic cord along with the deep inguinal ring. Since the patient already had an inguinal incision, we decided to approach the proximal spermatic cord through a transabdominal, extraperitoneal approach.

The histopathology report for the resected spermatic cord segment was negative for proximal resected end and positive for distal end.

The postoperative course was uneventful except for seroma formation at the incision site, which was managed conservatively. The patient is currently receiving adjuvant radiotherapy.

\section{DISCUSSION}

$\mathrm{MM}$ arises from the mesothelial lining of the body's serous cavities, that is, pleura, pericardium, peritoneum and its outpouching into the spermatic cord and scrotal sac, the tunica vaginalis. ${ }^{1}$

Primary spermatic cord $\mathrm{MM}$ is an extremely rare tumour with only 12 cases reported to date. ${ }^{2-4}$ It comprises of a larger group of paratesticular malignant mesotheliomas, which comprise $0.3 \%$ to $1.4 \%$ of all $\mathrm{MM}^{2}$ MMs of the paratesticular region commonly present as hydrocoeles and/or inguinoscrotal swellings mimicking more common lesions of this region. ${ }^{5} 6$ These tumours are most common in the 55-75-year-age group. ${ }^{5}$
Risk factors include asbestos exposure (present in 35\% cases), trauma, long-standing hydrocoele and herniorraphy. ${ }^{78}$

The initial imaging modality is ultrasonography, while CT scan and MRI can further characterise the lesion and help find metastatic secondaries. Retroperitoneal lymph nodal metastasis can be detected in $15 \%$ of cases with CT scan. ${ }^{9}$ Para-aortic lymph nodes are the most frequently and primarily involved whereas pelvic (iliac and obturator) nodes are involved in advanced stages. ${ }^{4}$

On histopathology, MMs have been subclassified into three groups: the epithelial type, most often seen in the peritoneal cavity and the tunica vaginalis; the mesenchymal or sarcomatous type, commonly found in the pleural cavity; and the biphasic or mixed type, which occurs in serosal membranes. ${ }^{10}$ The pure sarcomatous type of $\mathrm{MM}$ is very rare. ${ }^{11}$ For definitive diagnosis, the best positive immunohistochemical (IHC) markers are Calretinin, cytokeratin 5/6 and WT1, whereas the best negative IHC markers are CEA, MOC-31, Ber-EP4, BG-8 and B72.3. ${ }^{12}$ Vimentin can provide variable results on IHC for MM. ${ }^{4}$

Paratesticular MM is an aggressive tumour with a propensity for local recurrence and lymphatic and haematogenous metastases. Age $<60$ years is a significant positive prognostic marker whereas positive lymph nodes and primary metastatic disease are significant negative prognostic markers. ${ }^{5}$

Radical inguinal orchidectomy via an inguinal incision is accepted as the first-line surgical treatment. ${ }^{5}$ Frozen section assessment during surgery for suspicious inguinoscrotal masses can help the operating surgeon avoid unnecessary radical orchidectomy and help preserve healthy testes in cases of a 
benign diagnosis. ${ }^{13}$ In a retrospective analysis of 170 cases (159 testicular and 11 paratesticular) of intraoperative frozen section examination by Silverio et al, ${ }^{14}$ all the benign lesions were correctly identified with a failure rate of $3.5 \%$ in identifying malignant lesions when compared to final histopathological diagnosis, with a specificity and sensitivity of $100 \%$ and $95 \%$, respectively.

Plas et $\mathrm{al}^{5}$ found that $60 \%$ and $92.9 \%$ of the tumour recurrence occurred within the first 2 and 5 postoperative years, respectively. Therefore, follow-up surveillance and adjuvant therapy are strongly recommended. A variety of adjuvant treatments have been tried including radiotherapy, chemotherapy and combined chemoradiotherapy, though Plas ${ }^{5}$ found radiotherapy to be the most effective adjuvant therapy in his review of 73 published cases.

Owing to the rarity of paratesticular MMs, precise evidence about optimal management is lacking. So, the evidence for systemic chemotherapy in these cases has to be extrapolated from trials in pleural and peritoneal MM cases. The current standard first-line chemotherapy for pleural MM is an antifolate agent, pemetrexed with cisplatin. This combination has demonstrated a survival benefit (median survival time 12.1 vs 9.3 months) compared to cisplatin alone in a randomised phase III trial. ${ }^{15}$ Similar overall median survival of $12-14$ months has been obtained in peritoneal MM with antifolate (pemetrexed/raltitrexed) and cisplatin combinations. ${ }^{16}$ Selected patients of peritoneal MM who are candidates for curative treatment undergo cytoreductive surgery with hyperthermic intraperitoneal chemotherapy, which has improved overall 5 -year survival rate in this subset of patients to $29-63 \% .{ }^{16} 17$ Extrapolating the current evidence to our case, the patient could also be a good candidate for adjuvant systemic chemotherapy with pemetrexed and cisplatin instead of adjuvant radiotherapy.

In conclusion, MMs of the paratesticular region are difficult to diagnose preoperatively. Once confirmed, patients should be treated aggressively with surgery and adjuvant therapy. Long-term follow-up is desirable.

\section{Learning points}

Malignant mesotheliomas of the paratesticular region:

- Can present as common inguinoscrotal ailments such as hydrocoele and inguinoscrotal mass.

- Are aggressive and recurrent tumours with local and distant metastasis.

- Require prompt surgical treatment with adjuvant therapy.

- Need long term follow-up.
Contributors ZA participated in acquisition of data, analysis and interpretation of data, drafting the article, critical revision of the article and final approval of the version to be published. SS was responsible for critical revision of the article, analysis and interpretation of data, conception and design and final approval of the version to be published. AkM was involved in acquisition of data, analysis and interpretation of data, critical revision of the article and final approval of the version to be published. AlM participated in critical revision of the article, analysis and interpretation of data and final approval of the version to be published. All the authors agree to be accountable for the article and to ensure that all questions regarding the accuracy or integrity of the article are investigated and resolved.

Competing interests None declared.

Patient consent Obtained.

Provenance and peer review Not commissioned; externally peer reviewed.

\section{REFERENCES}

1 Mutsaers SE. The mesothelial cell. Int J Biochem Cell Biol 2004;36:9-16.

2 Meng X, Guzzo TJ, Bing Z. Malignant mesotheliomas in spermatic cords: reports of two cases and a brief review of literature. Rare Tumors 2013;5:e4.

3 D'Antonio A, Mastella F, Colucci A, et al. Malignant mesothelioma of spermatic cord in an elderly man with a history of asbestos exposure. Urology 2016;87:e1-3.

4 Park YJ, Kong HJ, Jang $\mathrm{HC}$, et al. Malignant mesothelioma of the spermatic cord. Korean J Urol 2011;52:225-9.

5 Plas $\mathrm{E}$, Riedl $\mathrm{CR}$, Pflüger $\mathrm{H}$. Malignant mesothelioma of the tunica vaginalis testis: review of the literature and assessment of prognostic parameters. Cancer 1998:83:2437-46.

6 Yen $\mathrm{CH}$, Lee $\mathrm{CT}$, Su CJ, et al. Malignant mesothelioma of the tunica vaginalis testis: a malignancy associated with recurrent epididymitis? World I Surg Oncol 2012;10:238.

7 Akin Y, Bassorgun I, Basara I, et al. Malignant mesothelioma of tunica vaginalis: an extremely rare case presenting without risk factors. Singapore Med J 2015;56:e53-55.

8 Gürdal M, Erol A. Malignant mesothelioma of tunica vaginalis testis associated with long-lasting hydrocele: could hydrocele be an etiological factor? Int Urol Nephrol 2001;32:687-9.

9 Garcia De Jalón A, Gil P, Azúa-Romeo J, et al. Malignant mesothelioma of the tunica vaginalis. Report of a case without risk factors and review of the literature. Int Urol Nephrol 2003;35:59-62.

10 Eimoto T, Inoue I. Malignant fibrous mesothelioma of the tunica vaginalis: a histologic and ultrastructural study. Cancer 1977;39:2059-66.

11 Bisceglia M, Dor DB, Carosi I, et al. Paratesticular mesothelioma. Report of a case with comprehensive review of literature. Adv Anat Pathol 2010;17:53-70.

12 Ordóñez NG. The immunohistochemical diagnosis of mesothelioma: a comparative study of epithelioid mesothelioma and lung adenocarcinoma. Am J Surg Pathol 2003:27:1031-51.

13 Subik MK, Gordetsky J, Yao JL, et al. Frozen section assessment in testicular and paratesticular lesions suspicious for malignancy: its role in preventing unnecessary orchiectomy. Hum Pathol 2012;43:1514-19.

14 Silverio PC, Schoofs F, Iselin CE, et al. Fourteen-year experience with the intraoperative frozen section examination of testicular lesion in a tertiary university center. Ann Diagn Pathol 2015;19:99-102.

15 Vogelzang NJ, Rusthoven JJ, Symanowski J, et al. Phase III study of pemetrexed in combination with cisplatin versus cisplatin alone in patients with malignant pleural mesothelioma. J Clin Oncol 2003;21:2636-44.

16 Mirarabshahii P, Pillai K, Chua TC, et al. Diffuse malignant peritoneal mesothelioma -an update on treatment. Cancer Treat Rev 2012;38:605-12.

17 Yan TD, Deraco M, Baratti D, et al. Cytoreductive surgery and hyperthermic intraperitoneal chemotherapy for malignant peritoneal mesothelioma: multi-institutional experience. J Clin Oncol 2009;27:6237-42.

Copyright 2016 BMJ Publishing Group. All rights reserved. For permission to reuse any of this content visit http://group.bmj.com/group/rights-licensing/permissions.

BMJ Case Report Fellows may re-use this article for personal use and teaching without any further permission.

Become a Fellow of BMJ Case Reports today and you can:

- Submit as many cases as you like

- Enjoy fast sympathetic peer review and rapid publication of accepted articles

- Access all the published articles

- Re-use any of the published material for personal use and teaching without further permission

For information on Institutional Fellowships contact consortiasales@bmjgroup.com

Visit casereports.bmj.com for more articles like this and to become a Fellow 